\title{
OPTIMAL INEQUALITIES INVOLVING POWER-EXPONENTIAL MEAN, ARITHMETIC MEAN AND GEOMETRIC MEAN
}

\section{ZHEN-HANG YANG AND JINGFENG TIAN}

Abstract. For $a, b>0$ with $a \neq b$, the power-exponential mean is defined by

$$
Z \equiv Z(a, b)=\exp \left(\frac{a \ln a+b \ln b}{a+b}\right)=\sqrt{a b} e^{t \tanh t},
$$

where $t=\ln \sqrt{a / b}$. In this paper, we prove the double inequality

$$
\left(\frac{Z^{p}+G^{p}}{2}\right)^{1 / p}<A<\left(\frac{Z^{q}+G^{q}}{2}\right)^{1 / q}
$$

holds for $a, b>0, a \neq b$ with the best constants $p=2 / 3$ and $q=1$, where $A=(a+b) / 2$, $G=\sqrt{a b}$. We also establish the sharp bounds for $e^{t \tanh t}$ as follows:

$$
\begin{aligned}
& 1<\frac{e^{t \tanh t}}{2 \cosh t-1}<1.055, \\
& \frac{1}{\sqrt{2}}<\frac{e^{t \tanh t}}{2(\cosh t)^{2 / 3}-1}<1
\end{aligned}
$$

for $t>0$. These improve some known results.

Mathematics subject classification (2010): Primary 26E60, 33B10, Secondary 26D20, 26 A48. Keywords and phrases: Mean, hyperbolic function, inequality.

\section{REFERENCES}

[1] G. D. Anderson, M. Vamanamurthy And M. Vuorinen, Monotonicity rules in calculus, Amer. Math. Monthly 113, 9 (2006), 805-816.

[2] M. BIERNACKI AND J. KRZYZ, On the monotonity of certain functionals in the theory of analytic functions, Annales Universitatis Mariae Curie-Sklodowska, 9 (1995), 135-147.

[3] D. Farnsworth And R. OrR, Gini means, Amer. Math. Monthly 93, 8 (1986), 603-607.

[4] C. Gini, Diuna formula comprensiva delle media, Metron, 13 (1938), 3-22.

[5] E. Neuman AND J. SÁNdor, Companion inequalities for certain bivariate means, Appl. Anal. Discrete Math. 3, 1 (2009), 46-51.

[6] E. NeumAn AND J. SÁNDOR, On certain means of two arguments and their extensions, Int. J. Math. Math. Sci., 16 (2003), 981-993.

[7] I. Pinelis, L'Hospital type rules for oscillation with applications, J. Inequal. Pure Appl. Math. 2, 3 (2001), Art. 33.

[8] Zs. PÁles, Comparison of two variable homogeneous means, General Inequalities 6. Proc. 6th Internat. Conf. Math. Res. Inst. Oberwolfach, Birkhäuser Verlag Basel, 1992.

[9] Zs. PÁLES, Inequalities for sums of powers, J. Math. Anal. Appl., 131 (1988), 265-270.

[10] J. SÁNDOR, On the identric and logarithmic means, Aequat. Math., 40 (1990), 261-270.

[11] J. SÁNDOR, A note on some inequalities for means, Arch. Math. (Basel), 56 (1991), 471-473.

[12] J. SÁNDOR, A note on the Gini means, Gen. Math. 12, 4 (2004), 17-21. 
[13] J. SÁNDOR AND B. A. BHAYO, On some inequalities for the identric, logarithmic and related means, J. Math. Inequal. 9, 3 (2015), 889-896.

[14] J. SÁndor And G. ToAder, On some exponential means Part II, Int. J. Math. Math. Sci., 2006 (2006), Art. ID 51937, 9 pages.

[15] J. SÁndor, G. ToAder And I. RASA, The construction of some means, Gen. Math., 4 (1996), 63-71.

[16] Z.-H. YANG, A new way to prove L'Hospital monotone rules with applications, arXiv:1409.6408 [math.CA].

[17] Z.-H. YANG, Bivariate log-convexity of more extended means and its applications, arXiv: 1408.2252 [math.CA].

[18] Z.-H. YANG, On the homogeneous functions with two parameters and its monotonicity, J. Inequal. Pure Appl. Math. 6, 4 (2005), Art. 101. 11 pages.

[19] Z.-H. YANG, On the log-convexity of two-parameter homogeneous functions, Math. Inequal. Appl. 10, 3 (2007), 499-516.

[20] Z.-H. YANG, On the monotonicity and log-convexity of a four-parameter homogeneous mean, J. Inequal. Appl., 2008 (2008), Art. ID 149286, 12 pages.

[21] Z.-H. YANG, Some identities for means and applications, RGMIA Res. Rep. Coll. 8, 3 (2005), Art. 17.

[22] Z.-H. YANG, The log-convexity of another class of one-parameter means and its applications, Bull. Korean Math. Soc. 49, 1 (2012), 33-47. 